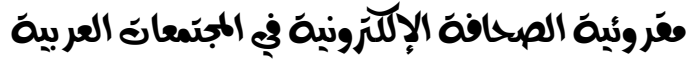

\section{مقروئية الصحافة الإلكترونية في المجتمعات العربية}

\section{دراسة ميدانية على عينة من الدول العربية}

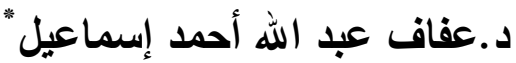

لقد شهذ الإعلام العربي على مستوى تكنولوجيّا الإعلام والاتصال تحولات كثيرة خلال العقدين الماضيين، ومن أبرز ملامحها ظهور شبكة الانترنت كوسيلة اتصال تفاعلية أتاحت الفرصة أمام الأفراد والجماعات والمؤسسات للوصول إلى المعلومات وبحجم هائل وبسرعة فائقة، وإرسالها ونشرها على نطاق واسع لم يسبق له مثثيل في التاريخ. ونظراً للفرص الكبيرة المتنوعة والمتعددة الأبعاد التي أتاحتها شبكة الإنترنت للاتصال، أضحت استخداماتها المختلفة، ومنها على الخصوص الإعلامية، مما أدى إلى إفراز أنماط إعلامية جديدة، وأبرزها ما بسمى بالصحافة الإلكترونية، ومن القضايا المهمة المرتبطة بها المقروئية لذلك نجد العديد من الدراسات الإعلامية التي تتاولت مقروئية الصحافة. تهدف الدراسة بشكل رئيس إلى التعرّف على مقروئية الصحافة الإلكترونية بالمجتمعات العربية وينبثق من الهدف الرئيسي مجموعة من الأهداف الفرعية تتتمي هذه الدراسة إلى الدراسات الوصفيّة حيث يرتبط مفهوم البحث الوصفيّ بدراسة واقع الأحداث والظواهر والمواقف والآراء وتحليلها، وتفسيرها بغرض الوصول إلى استتناجات مفيدة، إما لتصحيح هذا الواقع، أو تحديثه، أو استكماله، أو تطويره، وتمثّل هذه الاستتناجات فهماً للحاضر ، يستهدف توجيه المستقبل. وفي هذا الإطار استخدمت الباحثة منهج المسح وكان مجتمع الدراسة الدول العربية، والعينة جمهور من بعض الدول العربية. وتوصلت الدراسة أن 87.6\% من أفراد العينة يقراعون الصحف الإلكترونية بأثكالها المختلفة 81.5\% المواقع الإخبارية

*أستاذ مشارك بجامعي القرآن الكريم والعلوم الإسلامية وقسم الصحافة والإعلام بجامعة جازان. 
د. عغاف عبد اللر إسماعبله

،70.1\% المجلات الإكترونية 51.7\% والمنتيات بنسبة 61.4\% والمدونات

58.7\%، وأوضح 49.1\% من أفراد العينة أنهم يفضلون الصحف الإلكترونية

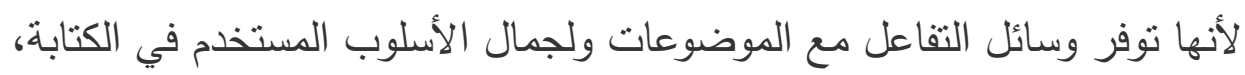

وبينت الدراسة أن أكثر الموضوعات التي يفضلها قراء الصحافة الإلكترونية

الموضوعات الاجتماعية وظهر ذلك بنسبة 62.3\%، وأكد أفراد العينة أن أكثر الكراه

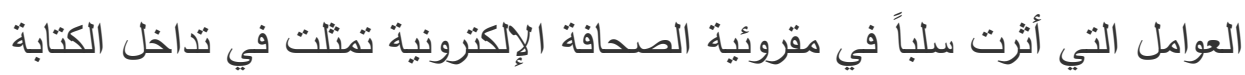

بنسبة 53.5\%، أما 51.7\% يرون السبب ضعف اللغة.

ABSTRACT
The Arab media, at the level of information and communication technology, has witnessed many transformations during the past two decades, and one of its most prominent features was the emergence of the Inter conviction Net Work (Internet) as an interactive means of communication that provided the opportunity for individuals, groups and institutions to access information of a huge size and very quickly or send it and spread it on a large scale in an unprecedented manner in history. In view of the large, varied and multidimensional opportunities provided by the Internet for communication, its various uses, including in particular the media uses, have led to the emergence of new media patterns, the most prominent of which is the so-called Electronic Journalism (EJournalism or Multi-Platform Journalism), including the important issues related to readability, so we find many media studies that dealt with the readability of the press (journalism).

The study mainly aims to identify the readability of electronic journalism in Arab societies, and a set of secondary objectives stems from the main objective.

The present study belongs to descriptive studies where the concept of descriptive research is related to studying the reality of events, phenomena, attitudes and opinions, analyzing and interpreting them with the aim of reaching useful conclusions either to correct, update, complete or develop this reality. These conclusions represent an understanding of the present aimed at guiding the

العدد السادس 1442هـ - ديسمبر 2020م.

158

جامعة أم درمان الإسلامية مجلة علوم الاتصال 


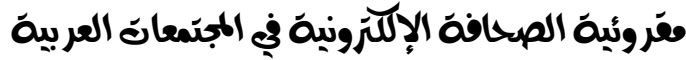

future. In this context, the girl researcher used the survey approach, and the study population was Arab countries, while the sample was from some Arab countries. The study concluded that $87.6 \%$ of respondents read online newspapers in their various forms, $81.5 \%$ read news websites, $70.1 \%$ read electronic magazines, $51.7 \%$ read forums, $61.4 \%$, and $58.7 \%$ blogs. $49.1 \%$ of respondents indicated that they prefer electronic newspapers because they provide means of interacting with topics and the beauty of the style used in writing. The study indicated that the topics that electronic journalism readers prefer most are social topics, and this appeared with a percentage of $62.3 \%$. The sample members (respondents) confirmed that the most negative factors affected the readability of the electronic journalism was represented in the overlap of writing by $53.5 \%$, while $51.7 \%$ saw the reason as weak and poor langue.

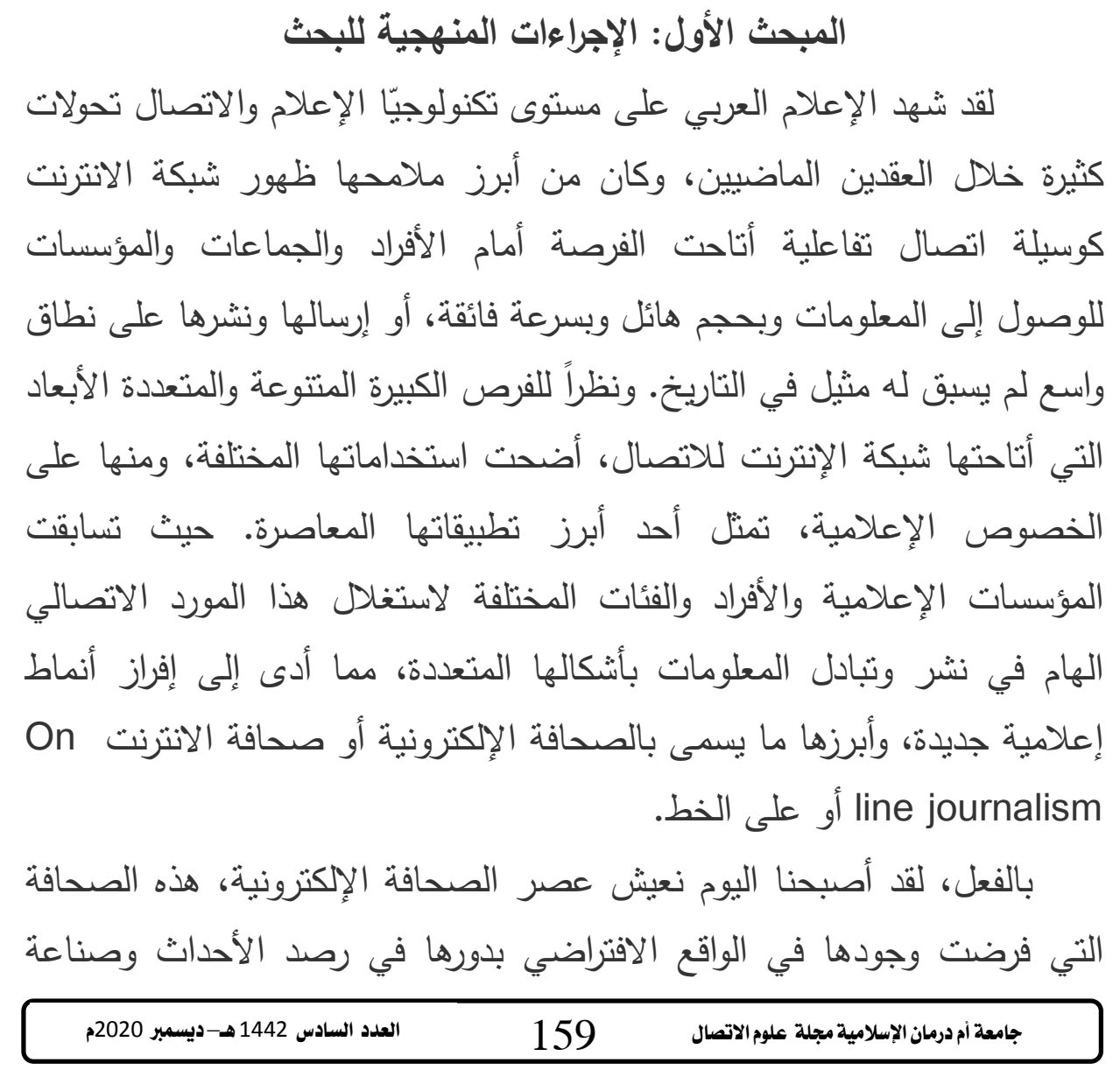




\section{د. ع دفاف عبر اللر إسماعبله}

الخبر • وهذا جنباً إلى جنب مع الصحافة التقليدية، ولتتجاوز القيود الجغرافية والسياسية التي نعاني منها نظيرتها الورقية. فالصحافة الإلكترونية تحرز تطوراً

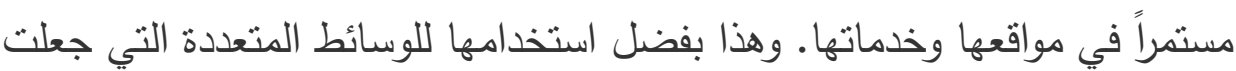
منها صحافة الكترونية تفاعلية. وتعد القراءة وسيلة هامة للتواصل ويمكن للإنسان عن طريقها الحصول على مختلف المعارف والثقافات وشغل أوقات الفراغ بما يفيد وينفع، وكانت القراءة مهمة وخاصة مع تطور العلوم المختلفة بما فيها وسائل الإعلام لذلك نجد العديد

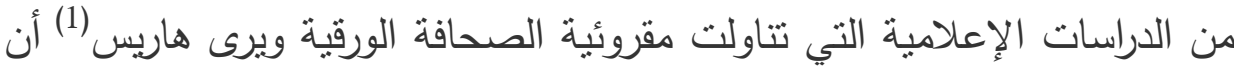
المقروئية تعتمد على عاملين الأول: يتعلق بالقارئ ، والثاني: يتعلق بالمادة

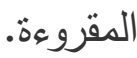

أما ما يتعلق بالقارئ يتمثل بالقدرة اللغوية للقارئ ودافعيته نحو نتاول نص

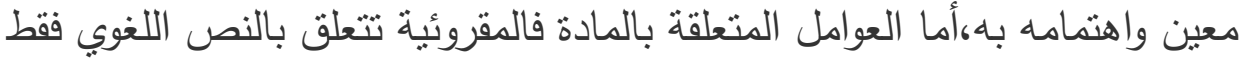
من خلال العديد من العوامل التي تؤثر في فهم المادة المكتوبة،فتهتم بالمفردات اللغوية التي تعد الأكثر أهية في تحديد صعوبة المادة المقروءة أو سهولتها ولكن في هذا البحث تناولت الباحثة مقروئية الصحافة الإلكترونية

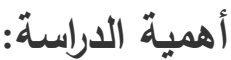
تكمن أهمية هذا البحث مقروئية الصحافة الإكترونية، لأن الصحافة الإلكترونية تعتبر من الهجالات الإعلامية الحديثة والتي حظيت باهتمام كبير من قبل الجماهير في مختلف أنحاء العالم ومن خلال البحث حاولت الباحثة قياس مقروئية الجمهور العربي لهذه الصحف والوقوف على العوامل التي تثؤثر في المقروئية.

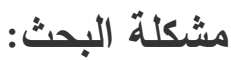

بالرغم من انتشار استخدام الإنترنت في الدول العربية وتعامل الجماهير

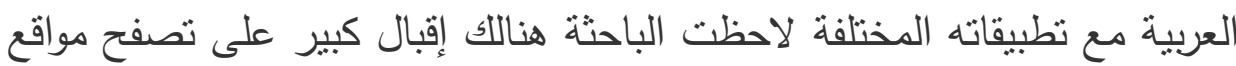




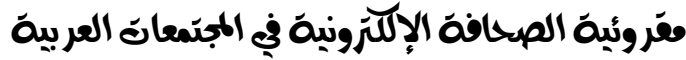

التواصل الاجتماعي المختلفة، لذلك تبادر إلى ذهن الباحثة سؤال هل تهنت الجماهير العربية بتصفح الصحف الإكترونية بنفس تصفحها لهواقع التواصل ؟

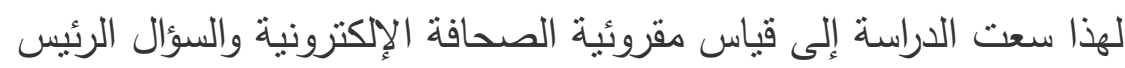

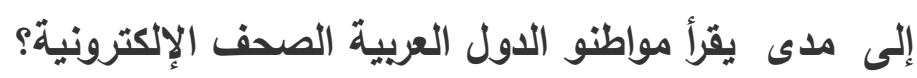
أهداف الاراسة

تهذف الدراسة بشكل رئيس إلى التعرّف على مقروئية الصحافة الإكترونية بالمجتمعات العربية وينبثق من الهذف الرئيسي الأهداف الفرعية الآتية:

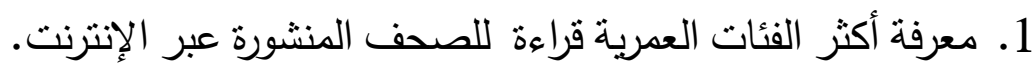
2. تحديد العوامل المؤثرة في مقروئية الصحافة الإلكترونية.

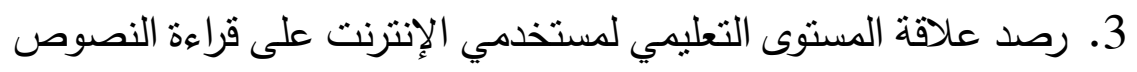
المكتوبة الكترونباً . 4. الوقوف على أكثر الصحف الإككترونية التي تحظى باهتمام القراء.

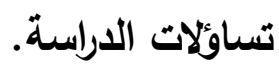
وتسعى هذه الدراسة إلى الإجابة عن التساؤلات الآتية:

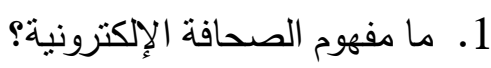
2. هل الصحف الإكترونية جاذبة لمواطني الدول العربية؟

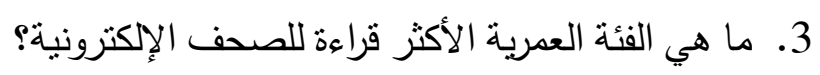

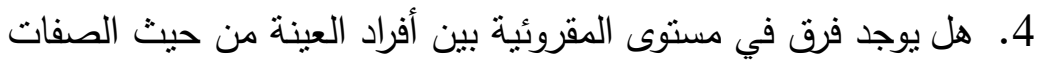

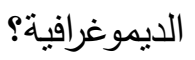
5. هل يؤثر اهتمام أفراد عينة الدراسة بالصحافة الإلكترونية على مستوى

$$
\text { المقروئية؟ }
$$

6. هل يجد القراء صعوبة في فهم الموضوعات المنشورة عبر الصحافة الإلكترونية؟

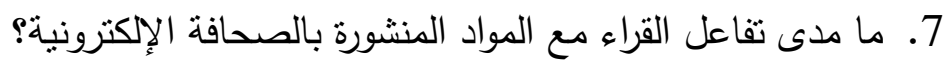

8. ما مدى مقروئية المبحوثين للصحف الورقية التي لها نسخة الكترونية؟ التراه 
9. ما هي العوامل التي تساعد الصحافة الإكترونية في المحافظة على مكانتها؟

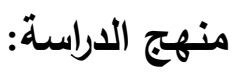
تتنمي هذه الدراسة إلى الدراسات الوصفيّة حيث برتبط مفهوم البحث الوصفيّ بدراسة واقع الأحداث والظواهر والمواقف والآراء وتحليلها، وتفسيرها بغرض الوصول إلى استنتاجات مفيدة، إما لتصحيح هذا الواقع، أو تحديثه، أو استكماله، أو تطويره، وتمثّل هذه الاستتاجات فهما للحاضر ، يستهدف توجيه

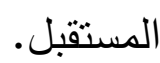

واستخدمت الباحثة منهج المسح لهذه الدراسة وهو أسلوب في البحث يتم من خلاله جمع المعلومات والبيانّات عن ظاهرة ما أو حدث أو واقع وذلك بقصد وهد التعرف على الظاهرة التي ندرسها وتحديد الوضع الحالي لها والتعرف على جوانب القوة والضعف فيها من اجل معرفة مدى صلاحية هذا الوضع أو مدى الحاجة لأحداث تغيرات جزئيّة أو أساسية فيه.

$$
\text { أدوات الدراسة (الإستبانة): }
$$

من أجل تحقيق أهداف الدراسة تم استخدام الإستبانة، وتم إعدادها بعد الاطّّلاع على الأدب النظري المتعلق بموضوع الدراسة مقروئية الصحافة الإكترونية بالمجتمعات العربية سواء ما توفر منها في الكتب والمراجع والدراسات الدوريات أو من المصادر الأخرى، وتم اختيار العينة من الجماهير من بعض فئه الدول العربية منها الخليج العربي ومصر والسودان. مفهوم وتعريف الصحافة الإكترونية

لقد تطرق العديد من الباحثين والإعلاميين إلى ظاهرة الصحافة الإلكترونية،

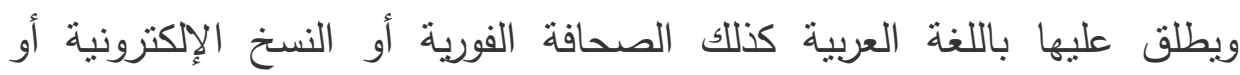
Electronic Newspaper الصحافة الرقمية، والتي يعبر عنها باللغة الانجليزية Virtual Newspaper, Electronic Journalism,Electronic Edition, 


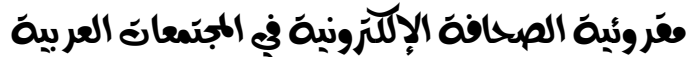

و online journalism و Digital Newspaper المتتبع لمفهوم الصحافة الإلكترونية منذ نشأتها يجد تعريفات مختلفة تختلف باختلاف مجال الاختصاص، وحسب علمنا لا يوجد تعريف واحد يحظى بالإجماع، ولكن يمكن أن نقدم بعض التعريفات التي تخدم بحثنا ومن زوايا متتوعة لتفادي التكرار، وعليه، سنذكر بعض التعريفات المهمة على النحو التالي: - عرفت أنها (صحافة تتم ممارستها على الخط المباشر)(2). نرى أن هذا التعريف قد حصر مفهوم الصحافة الإلكترونية في نوع واحد، أي الصحافة التي تمارس على الخط مباشرة ولكن الصحافة الإلكترونية أوسع من هذا التعريف بكثير

-الصحافة الإلكترونية هي الصحافة غير الورقية، مقروءة ومسموعة ومرئية، تبث محتوياتها عبر مواقع لها على الثبكة المعلومات العالمية(3). إذن، فمنل هذا التعريف يركز على ما هو غير ورقي. -وضع الصحيفة اليومية الكبيرة على الخط، أب جعلها في مثتاول القراء عبر كمبيوثز مجهز بمودم(4). ومثل هذا التعريف يعتبر ناقصاً أو غير مطابق لطبيعة الصحافة الإلكترونية، حيث توجد هذه الأخيرة في شكل الكتروني ولا يوجد لها

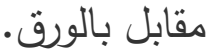

- يرى آخرون أنها المنشور الدوري يحتوي على الإحداث الجارية المرتبطة بموضوعات ذات طبيعة عامة، أو موضوعات ذات طبيعة خاصة، ويتم قراءتها من خلال جهاز الحاسب وغالباً ما تكون مناحة عبر شبكة الإنترنت، ويؤكد هذا بعضهح بقوله إن الصحافة الإلكترونية تطلق على عملية الإنتاج والنشر، وذلك من خلال توظيف الحاسبات الآلية في خطوات إنتاج الصحيفة، أو مراحل النشر الصحفي. 


\section{د. مغافه عبد اللر إسماعبل}

-تثمتل الفكرة الأساسية في الصحيفة الإلكترونية، في توفير المادة الصحفية للقراء على إحدى شبكات الخذمة التجارية الفورية، مستخدمة في ذلك تقنيات حديثة ظهرت كوليدة لتكنولوجيا الاتصال، طارحة العديد من التحديات بالنسبة للوسائل

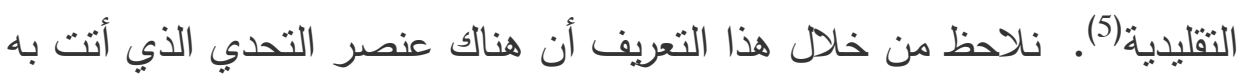

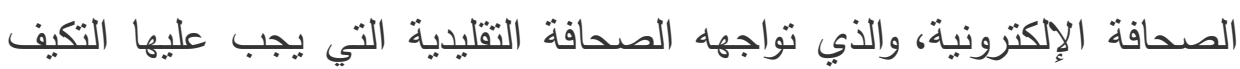
مع المنافسة الجديدة على أكثر من صعيد.

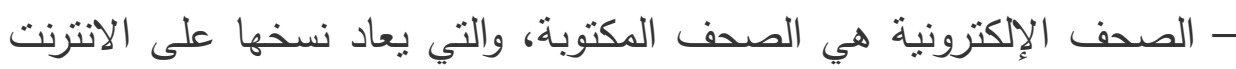

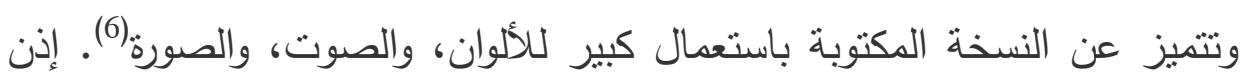

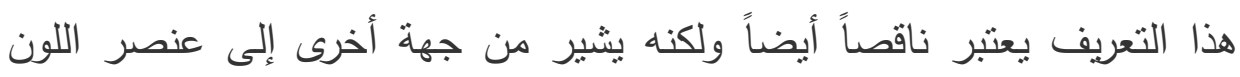
ونوعيته في التعريف، وهو ما يميز الصحافة الإلكترونية عن الصحافة التقليدية.

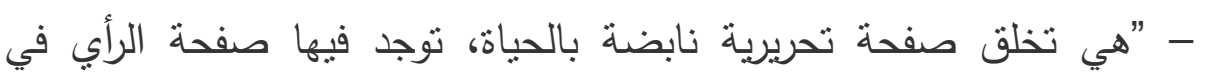
مواجهة الصفحات التي تحوي رسائل القراء وهو ما لا يوجد في الصحيفة اليومية.

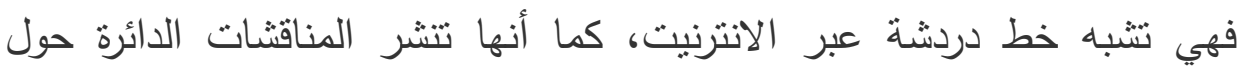

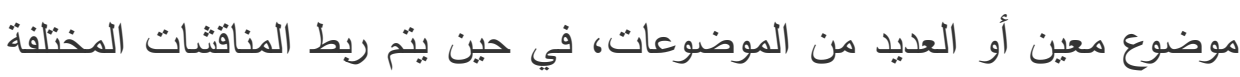

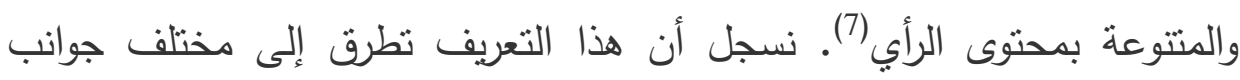
خصائص الصحافة الإلكترونية بصفة شمولية ومختصرة.

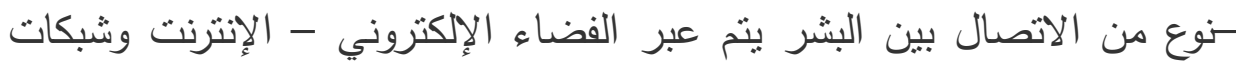

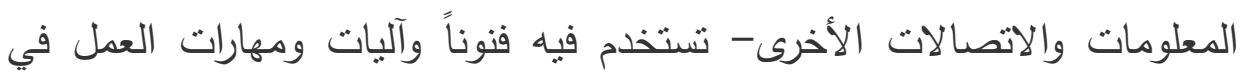

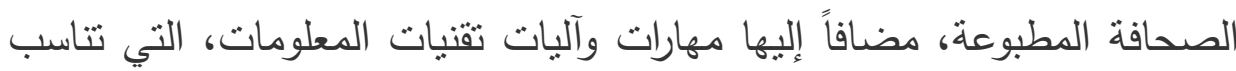
استخدام الفضاء الإكتروني كوسيط أو وسيلة الاتصال، بما في ذلك استخدام

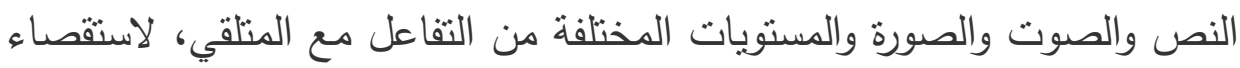

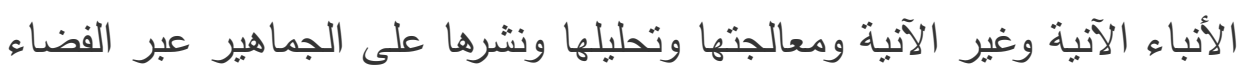




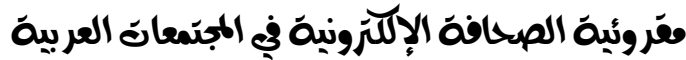

الإلكتروني بسرعة. يعتبر هذا التعريف مهم للغاية حيث يشير إلى عناصر تفتقد في التعريفات الأخرى كالوسائط المتعددة والتفاعلية. - -موذج جديد في العمل الصحفي، يستغل كافة مميزات وتقنيات الانترنت، يجعل

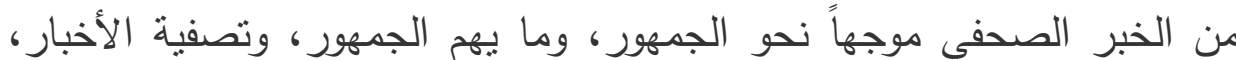
بحيث يحصل القارئ على ما يهمه دون الآلتفات إلى الاهتمامات التجارية والإعلانية. أطلق على هذا النموذج اسم الصحافة الموزعة Distributed journalism أو الصحافة التفاعلية Interactive journalism.(8) بين لنا هذا التعربف أن الصحافة الإلكترونية صحافة تفاعلية بالدرجة الأولى. -الصحافة الإلكترونية نوع إعلامي لوسيلة إعلامية تتحقق بفكرة النشر الالكتروني، الذي بدوره يتجسد من خلال الانترنت، كثبكة معلوماتية وأداة ومصدر للمعلومة. ومما سبق نستتتج أن كل باحث عرف الصحافة الإلكترونية حسب خصائصها أو وظيفتها، وتكاد التعريفات تتعدد بتعدد الكتاب.

حاول بعض الباحثين تقديم تعريف شامل للصحافة الإلكترونية (هي الصحف التي يتم إصدارها ونشرها على شبكة الانترنت سواء كانت هذه الصحف بمثابة نسخ أو إصدارات الكترونية لصحف ورقية مكتوبة أو ورقية مطبوعة أو موجز لأهم محتويات النسخ الورقية أو جرائد أو مجلات الكترونية ليست لها إصدارات مطبوعة ، وهي تتضمن مزيجاً من الرسائل الإخبارية والقصص والمقالات والتعليقات والصور الخدمات المرجعية). ويلاحظ من التعريفات المختلفة التالي:

1. الاتفاق على أن الصحافة الإكترونية لا تأخذ الشكل الورقي المطبوع حتى

$$
\text { وإن كانت ذات أصل ورقي. }
$$

2. مستخدم الصحافة الإكترونية يقوم باستدعائها من شبكة المعلومات. 


\section{د. عغافه عبر اللر إسماعبله}

3. محتواها ليس نصوصاً فقط ، فيمكن أن تضم الصوت والصورة الثابتة

والمتحركة والرسوم أي متعددة الوسائط Multimedia.

نشأة الصحافة الإلكترونية وتظورها:

تاريخ انطلاق أول صحيفة الكترونية غير متفق عليه حيث تتباين الروايات بهذا الثأن. وعليه، ومع اتجاه المزيد من الناس نحو الإنترنت، كمورد

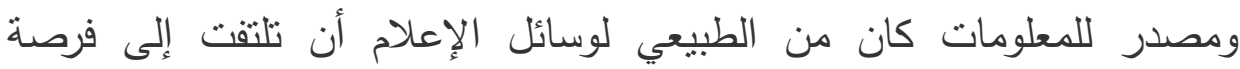

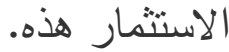

يرى بعض الباحثين أن ظهور الصحافة الإلكترونية كان مع بداية السبعينات،

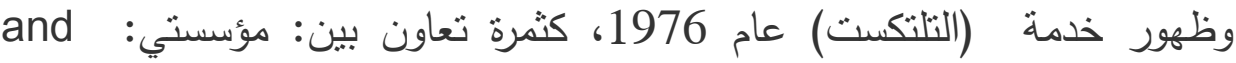
Independent Broadcasting BBC British علفيديوتكست الأكثر تفاعلية مع نظام Prestel على يد مؤسسة Telecom Authority المذكورة في توفير خدمة النصوص التفاعلية للمستفيدين، دخلت بعض المؤسسات

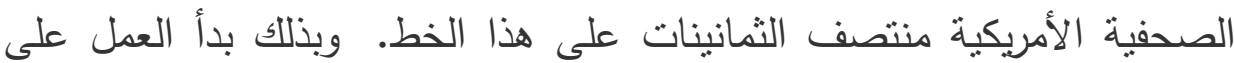
توفير النصوص الصحفية بشكل الكتروني إلى المستفيدين عبر الاتصال الفوري

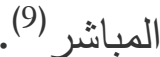
إلا أن هذه المحاولات لم ثلق النجاح المطلوب، وتكبدت خسائر مالية قدرت حينها ب 200 مليون دولار أمريكي. لذلك توقفت مشاريع تلاك المؤسسات الصحفية، ويرجع المختصون البداية غير الموفقة للصحيفة الإلكترونية، إلى عدم توفر تقنيات متطورة بما فيه الكفاية لتسمح بوصول غير مكلف وسهل إلى المحتوى الئى

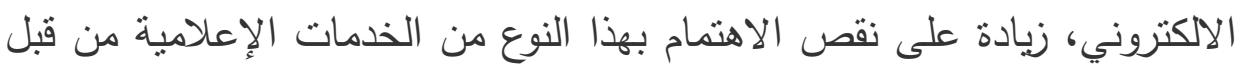
المعلنين والمستقيدين على حد سواء. لكن مع بداية التسعينات تطورت تقنيات النشر الآكتروني، إضافة إلى حاجة المستقيدين إلى الخدمات الإلكترونية. ولقد لقداني 


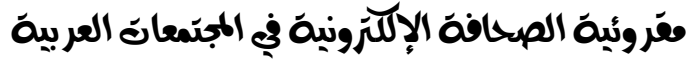

ارتبط نجاح خدمة التلتكست باعتمادها على جهاز التلفزيون، أما نجاح الصحيفة الإلكترونية في انطلاقتها الثانية فمرتبط بتوفر جهاز الحاسب الآلي وتطوره . وتعتبر صحيفة (هيلزنبرغ إجباد) السويدية أول صحيفة تتشر بالكامل على الإنترنت، وتلتها صحيفة "الواشنطن بوست، الأمريكية سنة 1994 والتي قامت بإعداد نشرة يعاد تحديثها فورياً في كل مرة تتغير فيها الأحداث، مع وجود مراجع وثائقية وتاريخية وإعلانات. وقد أطلق على هذا النوع من النشر في بدايته الأولى مصطلح الحبر الرقمي. وبالتالي، وقبل نهاية التسعينات، كانت هناك عشرات الصحف في العالم وخصوصاً الكبرى منها قد سخرت إمكانيات معتبرة لتشئ مواقع على شبكة الإنترنت نظراً لقلة التكلفة والسهولة، رامية بذلك المسعى إلى توسيع آفاق التوزيع والانتشار ، لتتجاوز التقييدات المالية والنقل وبصفة خاصة قيود الرقابة. إلا أنه سرعان ما اكتشف أصحاب الصحف أن النسخة الإلكترونية المشابهة للطبعة الورقية لم تعد تلبي احتياجات القراء، إذ إن المستخدم يبحث عن الجديد بعيداً عن الطبعة الورقية على الإنترنت. وهكذا، بدأت الصحف بإنشاء إدارات تحرير خاصة بمواقعها الإلكترونية تثولى تحرير جريدة منفصلة عن النسخة الورقية. وبالتالي، أصبحت الصحف الإلكترونية منافسة للصحف المطبوعة، كما أن الأهمية المتزايدة للصحافة الإلكترونية أدى إلى ظهور اتجاه آخر من هذه الصحف يتمثل في ظهور مواقع إخبارية الكترونية، تتخذ مظهر صحيفة متكاملة من حيث المضمون والمسمى. ولكن تخضع للنمط الإلكثروني وهي صحف الكترونية محضة لا علاقة لها بأي صحيفة ورقية، إذ نشأت في بيئة الانترنت وحققت نجاحاً كبيراً، حتى أن نجاحها شجع بعضها على الخوض في عالم النشر

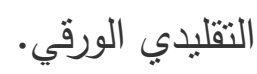




\section{د. عغافه عبر اللر إسماعبله}

وبحسب رأي الباحث الأمريكي (مارك ديويز) في دراسة له حول تاريخ الصحافة

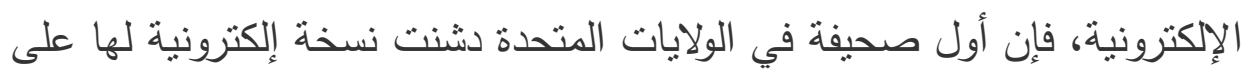
الإنترنت كانت (شيكاغو تريبيون) عام 1992 مع نسختها (شيكاغو اون لاينهان. وتوالى بعد ذللك ظهور المواقع الإخبارية والصحفية على الإنترنت، سواء التابعة

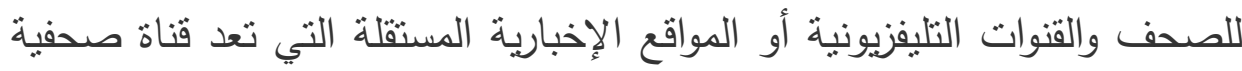
إلكترونية مستقلة في حد ذاتها.

يشير البعض أن الصحافة الإكترونية شهدت ازدهاراً كبيراً بعد الحادي

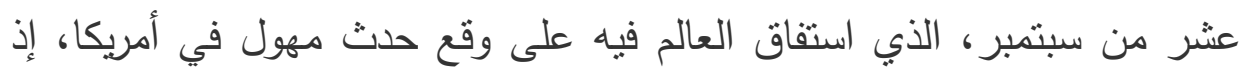
استطاعت الصحف الإكترونية والمواقع الإخبارية الإلكترونية أن تتقل بالكلمة

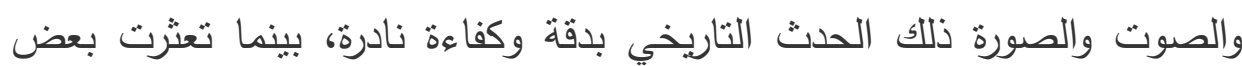

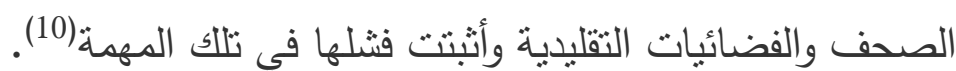
وتجدر الإثشارة إلى أن الصحف الإلكترونية لم تكن في البداية ذات عائد مادي

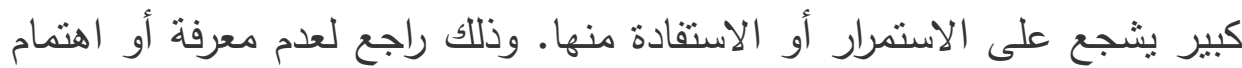

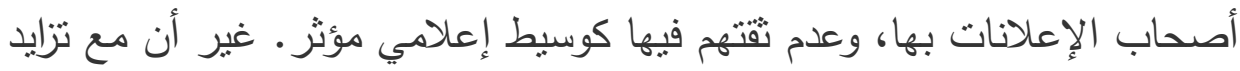
استخدامات الانترنت وكثرة رواد مواقع الصحف الإلكترونية تتبه المعلنون لأهمية

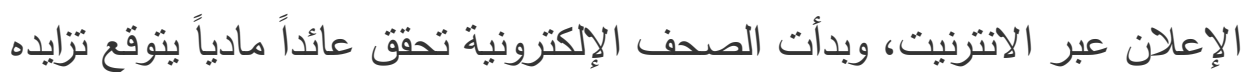
في المستقبل بشكل كبير جداً (11). ولقد كانت بداية الصحافة الإكترونية مجرد مواقع تحتوي على مقالات

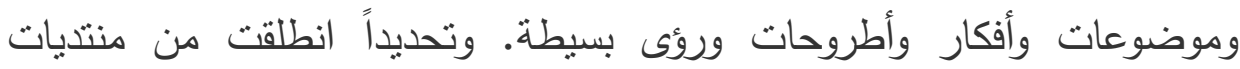

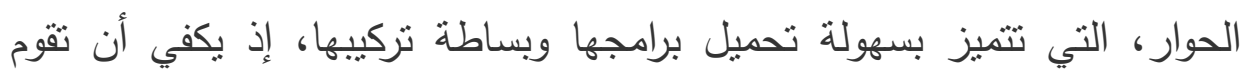
بتحميل هذه البرامج المجانية في الغالب ورفعها لموقعك في أقل من ساعة، ليبدأ بعدها الموقع بأثره في العمل المحدد له وفي اجتذاب عدد كبير من الزوار. 


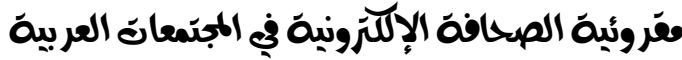

عوامل ظهور الصحافة الإكترونية وأنواعها: أولاً: عوامل ظهور الصحافة الإكترونية:

يرى بعض الباحثين أن هناك ثلاثة عوامل ساهمت في ظهور وتطور الصحافة

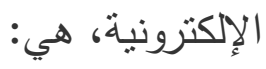

- الارتفاع في قدرات الكمبيوتر على التخزين ومعالجة المعلومات. - التقام في مجال ترقيم المعلومات فكل معلومة مشفرة في شكل رقمي، مما منحها

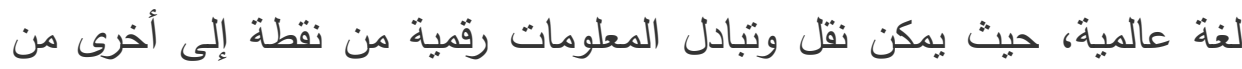

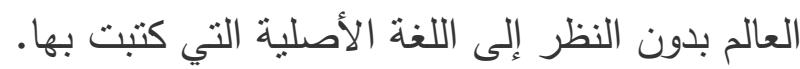
- نطور تقنية ضغط المعلومات وإزالة ضغطها والتي تمكن من إرسال المعلومات بسهولة، بدل تخصيص مساحات كبيرة تعرقل من عملية إرساله.

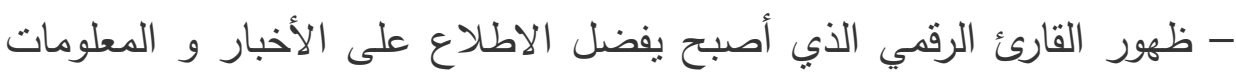
في المواقع الإلكترونية، لما تتمتع به من خصائص فنية كأن يتم تحديثها باستمرار، وتوفرها على كم هائل من المعلومات ويتم اقتناؤها بطرق تفاعلية مختلفة.

- مواجهة الصحف المكتوبة على المستوى العالمي صعوبة كبيرة، بسبب غلاء مادة الورق والطباعة وقلة المادة الإعلانية التي فضلت التلفزيون والانترنت (12).

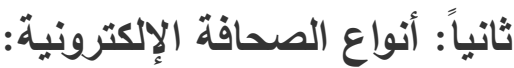

على الرغم من أن الأنواع المختلفة للصحافة الإكترونية تحمل قدراً واضحاً

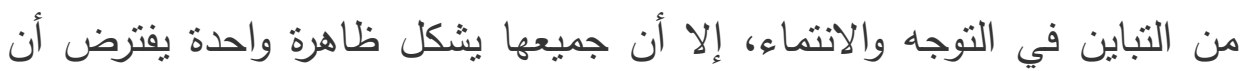

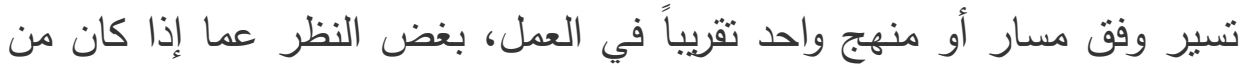

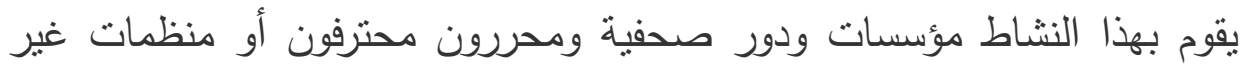
صحفية أو صحفيون هواة أو خلاف ذلك، لأن الدسار نابع من طبيعة الإنترنت

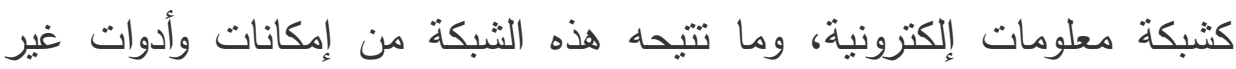




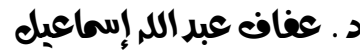

مسبوقة في ممارسة العمل الصحفي، وما تفرزه أيضاً من تحديات. فقد برزت مظاهر جديدة للصحافة الإككترونية شكلت امتداداً لمسيرة هذه الوسيلة الإعلامية

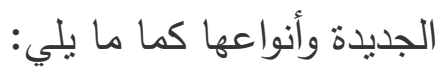
1- الصحف الإكترونية التي لها ما يقابلها من الصحف الورقية:

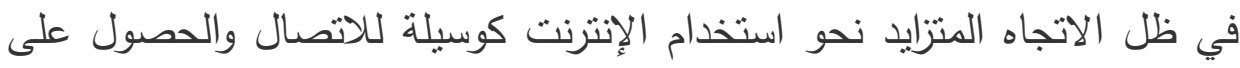

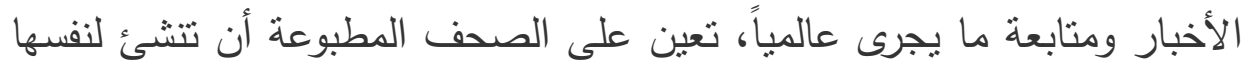

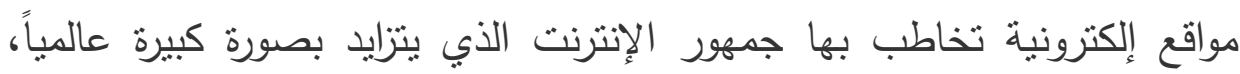
وتنتخدم كوسيلة لامتصاص واستيعاب صدمة المنافسة الناشئة عن اقتحام هذا المجال. ويزخر هذا المدخل بالعديد من النقاط الجديرة بالمناقثنة منل مستوى

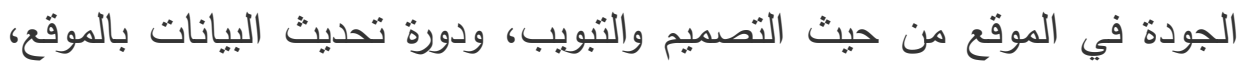

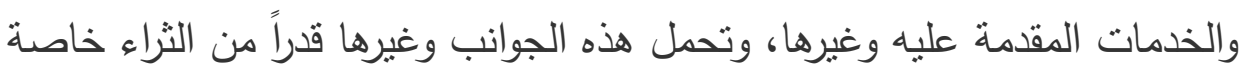
فيما يتعلق بمواقع الصحف العربية التي لم تدرس بالقدر الكافي رغم أن منابعتها

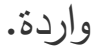

2- الصحف الإكترونية التي ليس لها ما يقابلها:

في عام 1999 ظهرت عبر الإنترنت موجة (الدوت كوم)، والتي يقصد بها

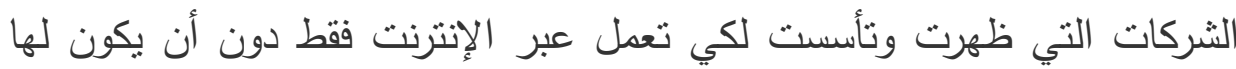

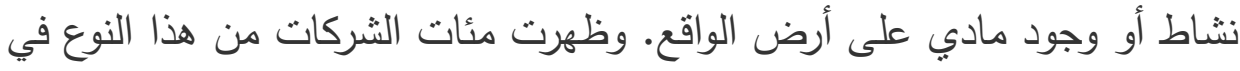
مجالات عديدة، شملت السياحة والسفر والتجارة الإلكترونية والدجالات العلمية العات العنات والصناعية وأيضاً المجال الإعلامي والصحفي. فتتكلت شركات لم تكن سوى مواقع على الثبكة تعمل في مجال الصحافة والإعلام، وعرفت باسم بوابات الإنترنت الصحفية، وتخصصت في تقديم المواد الإخبارية والتحليلات الصحفية والمقابلات والحوارات والمحادثة والنشرات البريدية الإلكترونية وخدمات البريد الإكتروني وخدمات البحث في الأرشيف. وحالياً تجسد هذه البوابات نموذجاً 


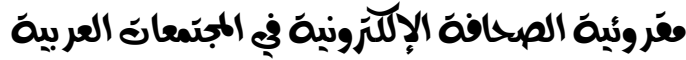

للصحافة الإكترونية التي تمارس عملها بالكامل عبر الإنترنت دون أن يكون لها

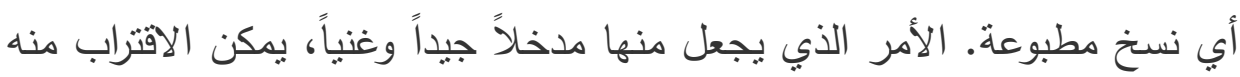
وفقاً للعديد من النقاط الخاصة بالتصميم ودورية التحديث وتتوع الخدمات، والجهات القائمة على الموقع وتوجهاته العامة والروئية التي يحملها القائمون عليه. 3- الامتدادات الإكترونية للمؤسسات غير الإعلامية: لقد أشرنا آنفاً إلى أن الطابع المفتوح لبيئة العمل الصحفي عبر الإنترنت فتح المجال واسعاً أمام العديد من الجهات غير الصحفية والإعلامية، لكي تمارس بنفسها وبشكل مباشر النشاط الصحفي بشكل أو بآخر. لذللك بمكن لمستخدم الثبكة أن يجد مئات المواقع الثهيرة التابعة لأحزاب سياسية ومنظمات محلية ودولية، وحركات سياسية وعسكرية بل وحكومات ودول، جميعها يقدم خدمات صحفية متتوعة عبر هذه المواقع، تشمل الخبر والرأي والتقارير المكتوبة والمصورة والتحليلات ولقطات فيديو وتسجيات حية وساحات النقاش والحوار وغيرها، مما يجعلنا أمام مظهر مستقل قائم بذاته من مظاهر الصحافة الإككترونية، تمتزج فيه السياسة والعلوم والاقتصاد بالصحافة، وتتلاشى فيه الحدود بين مصدر المعلومة والجهة القائمة على بثها ونقلها. الاراسة الميدانية (مقروئية الصحافة الإلكترونية): فالصحافة الموجودة على الإنترنت تتتافس فيما بينها، من أجل تقديم فكر متميز يجذب أكبر عدد ممكن من القراء والباحثين. وهذا التتافس الثريف الذي التي كان لوقت قريب ورقياً، قد أصبح اليوم ورقياً وإلكترونياً عبر شبكة الإنترنت، وهن، خاصة في ظل تعاظم القدرات الاقتصادية وتأسيس العديد من المؤسسات الصحافية. وتزايد عدد الإصدارات بإمكانيات تفوق منيلاتها في الدول العربية الأخرى. فقد انتقلت لتصبح منافسة في الرأي والتحليل عبر استقطاب أهم الأقلام المحلية والعربية والعالمية. 


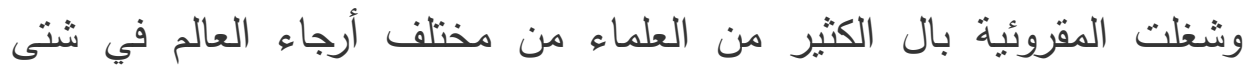
المجالات العلمية وكانت الحاجة الربط بين الكتابة والقراءة والبحث عن الأسباب

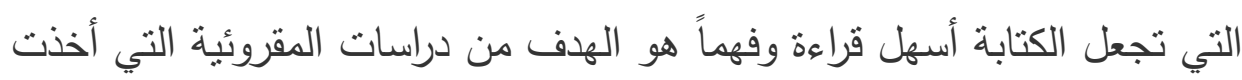
من اللغة الانجليزية (readability).

رغم اختلاف التعريفات إلا أنها تتفق في أن هدف المقروئية دراسة العوامل والأسباب التي تجعل قراءة النصوص المكتوبة وفهمها أسهل بالنسبة للقراء المعنيين، كما تهدف إلى وضع الوسائل التي تقيس مستوى النصوص المكتوبة من

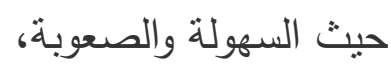

قراءة الصحف الإكترونية: يمكن القول عن الصحافة أنها محررة من القيد

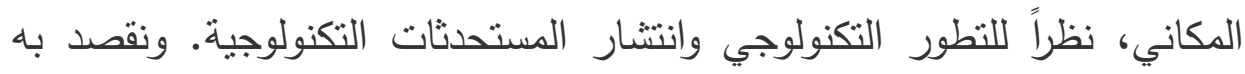
استقبال الانترنت مثناً أصبح جهاز الهاتق النقال الذكي smart phone وإككانية الحصول على الأخبار فورية.

مقروئية الصحافة الإكترونية العربية:

وتظل أبرز التحديات التي نواجهها الصحف الإلكترونية العربية، هيمنة الثقنيين وليس الصحفيين على إدارة الصحف الإلكترونية، من تحرير وتصميم

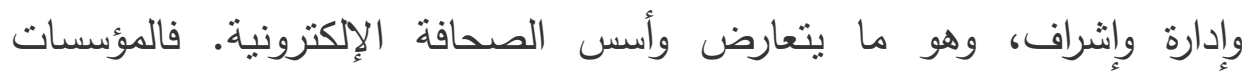
الصحفية تحتاج إلى إجراء تحولات تنظيمية في آليات الممارسة الصحفية السائدة

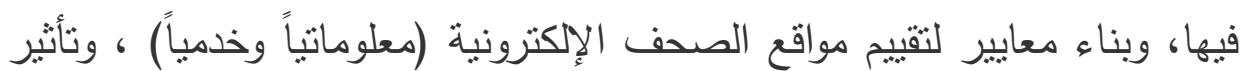
ذللك في مقروئية الصحافة الإلكترونية.

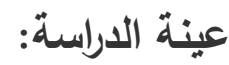
وللوقوف على مدى مقروئية الصحف الإكترونية أجرت الباحثة دراسة ميدانية على عينة من الجمهور بالوطن العربي قوامها 114 نم توزيع الإستبانة عليهم الإكرونه الكترونيا والجدول رقم(1) يوضح أعمارهم.

العدد السادس 1442هـ - ديسمبر 2020م 


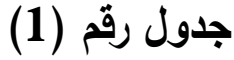

يبين أعمار المبحوثين

\begin{tabular}{|c|c|c|}
\hline النسبة الئوية & التكرار & الفئة \\
\hline 48.2 & 55 & أقل من 25 سنة \\
\hline 27.2 & 31 & سنة 35-26 \\
\hline 9.6 & 11 & سنه 45- 36 \\
\hline 15 & 17 & أكثر من 45 سنة \\
\hline 100 & 114 & المجموع \\
\hline
\end{tabular}

يوضح الجدول رقم (1) أن الثريحة الأكبر من المبحوثين أعمارهم أقل من 25 سنة وظهر ذلك بنسبة 48.2\% ومابين (26- 35 سنة) 27.23\% ، أما الذين

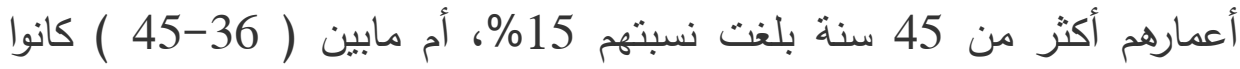
حوالي 9.6\% نتوصل إلى ذلك بأن حوالي 85\% من أفراد العينة لا تزيد أعمارهم عن 45 سنة وهي مرحلة الثباب .علماً بأن الثباب هم الأكثر استخداماً

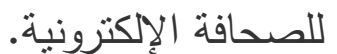

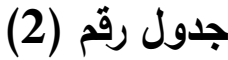

يوضح المستوى التعليمي لأفراد العينة

\begin{tabular}{|c|c|c|}
\hline النسبة المئوية & التكرار & الفئة \\
\hline 2.6 & 3 & المرحلة الثانوية \\
\hline 71 & 81 & المرحلة الجامعية \\
\hline 26.3 & 30 & فوق الجامعي \\
\hline 100 & 114 & المجموع \\
\hline
\end{tabular}

يبين الجدول رقم (2) بأن 71\% من أفراد العينة بالمرحلة الجامعية 26.3\% فوق الجامعي و2.6\% من المرحلة الثنانوية. 
د. عغاف عبر الكر إسماعبله

جدول رقم (3)

يوضتح عدد الساعات التي يقضيها المبحوثين في الاطلاع على الصحف

الإكترونية يومياً

\begin{tabular}{|c|c|c|}
\hline النسبة المئوية & التكرار & الفئة \\
\hline 3.5 & 4 & أقل من ساعة \\
\hline 62.2 & 71 & ساعات 2-4 \\
\hline 30.8 & 35 & ساعات 4-6 \\
\hline 3.5 & 4 & أكثر من 6 ساعات \\
\hline 100 & 114 & المجموع \\
\hline
\end{tabular}

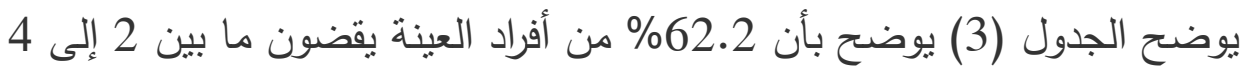

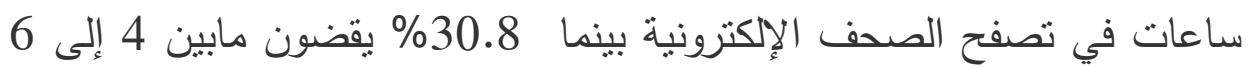
ساعات أما الذين يمضون أكثر من 6 ساعات بلغت نسبتهم 3.5\%

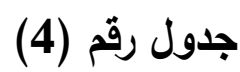

يبين متابعة المبحوثين لمواقع التواصل الاجتماعي

\begin{tabular}{|c|c|c|c|c|c|c|c|c|c|c|c|c|}
\hline \multicolumn{2}{|c|}{ اليوتيوب } & \multicolumn{2}{|c|}{ الفيسبوك } & \multicolumn{2}{|r|}{ تويتر } & \multicolumn{2}{|r|}{ الواتس } & \multicolumn{2}{|c|}{ انستقرام } & \multicolumn{2}{|c|}{ سناب شات } & الفئة \\
\hline$\%$ & التكرار & $\%$ & التكرار & $\%$ & التكرار & $\%$ & التكرار & $\%$ & التكرار & $\%$ & التكرار & الثياران \\
\hline 62.2 & 71 & 63.1 & 72 & 30.7 & 35 & 83.3 & 95 & 45.6 & 52 & 40.4 & 46 & دائما \\
\hline 29.8 & 34 & 20.2 & 23 & 33.3 & 38 & 13.2 & 15 & 29 & 33 & 19.3 & 22 & أهيانًا \\
\hline 7.9 & 9 & 16.7 & 19 & 35.9 & 41 & 3.5 & 4 & 25.4 & 29 & 40.4 & 46 & لا اتصفح \\
\hline 100 & 114 & 100 & 114 & 100 & 114 & 100 & 114 & 100 & 114 & 100 & 114 & الججموع \\
\hline
\end{tabular}

يبين الجدول رقم (4) أن أكثر مواقع التواصل الاجتماعي التي يستخدمه المبحوثين

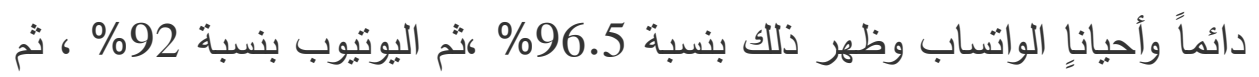
الفيسبوك بنسبة 83.3\% ، ثم الانستغرام بنسبة 74.6\% ، تويتر 64\%، والسناب

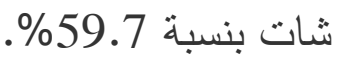

العدد السادس 1442هـ - ديسمبر 2020م 


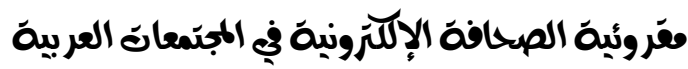

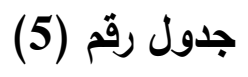

يوضح تصفح المبحوثين للصحافة الإكترونية

\begin{tabular}{|c|c|c|c|c|c|c|c|c|c|c|}
\hline \multicolumn{2}{|c|}{ المجلات الإلكترونية } & \multicolumn{2}{|c|}{ الصحف الإلكترونية } & \multicolumn{2}{|c|}{ المواقع الإخبارية } & \multicolumn{2}{|c|}{ المنتديات } & \multicolumn{2}{|r|}{ المدونات } & \multirow{2}{*}{ المئة } \\
\hline$\%$ & التكرار & $\%$ & التكرار & $\%$ & التكرار & $\%$ & التكرار & $\%$ & التكرار & \\
\hline 18.4 & 21 & 35.9 & 41 & 35.9 & 41 & 11.4 & 13 & 9.6 & 11 & دائما \\
\hline 51.7 & 59 & 51.7 & 59 & 45.6 & 52 & 50 & 58 & 49.1 & 56 & أحياناً \\
\hline 29.8 & 34 & 12.3 & 14 & 18.4 & 21 & 37.7 & 43 & 41.2 & 47 & لا اتصفح \\
\hline 100 & 114 & 100 & 114 & 100 & 114 & 100 & 114 & 100 & 114 & المجموع \\
\hline
\end{tabular}

يوضح الجدول رقم (5) بأن معظم المبحوثين يتابعون الصحف الإكترونية دائماً وأحياناً وكانت على النحو التالي المجلات والصحف الإلكترونية بنسبة 87.6\% الصحف الإكترونية،81.5\% للمواقع الإخبارية ، 70.1\% المجلات الإكترونية 51.7 والمنتديات بنسبة 61.4\% والمدونات 58.7\% و

جدول رقم (6)

يبين أسباب اختيار المبحوثين لصحيفتهم الإكترونية المفضلة

\begin{tabular}{|c|c|c|}
\hline النسبة المئوية & التكرار & الفئة \\
\hline 41.2 & 47 & وجود روابط ذات صله \\
\hline 34.2 & 39 & تصميهها الجذاب \\
\hline 39.5 & 45 & وجود عناصر تساعل على الفهم \\
\hline 49.1 & 56 & الاسلوب المستخدم في الكتابة \\
\hline 49.1 & 56 & توفر وسائل التفاعل مع الموضوعات \\
\hline
\end{tabular}

يبين الجدول رقم (6)وأوضح أفراد العينة بأنهم يقرعون صحفهم الإكترونية المفضلة لتوفر وسائل التفاعل مع الموضوعات والأسلوب المستخدم في الكتابة وظهر ذلك بنسبة 49.1\% ، بينما 47.2\% يتابعونها لوجود روابط ذات صلة في حين يتابعها بعض المبحوثين لوجود عناصر تساعد على الفهم بنسبة 39.5\%؛ أما الذين يتصفحونها من أجل تصميمها وذلك بنسبة 34.2\%. 
د. ع دافه عبر الكر إسماعبله

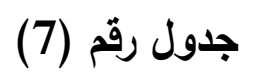

يوضح الموضوعات التي يحرص المبحوثين على قراعتها

\begin{tabular}{|c|c|c|}
\hline النسبة المئوية & التكرار & الفئة \\
\hline 57 & 65 & العلمية \\
\hline 54.4 & 62 & الدينية \\
\hline 45.6 & 52 & السياسية \\
\hline 58.8 & 67 & الثقافية \\
\hline 62.3 & 71 & الاجتماعية \\
\hline 29.8 & 34 & لاقتصادية \\
\hline 21.9 & 25 & الرياضية \\
\hline
\end{tabular}

يوضح الجدول رقم (7) أن المبحوثين بأن أكثر الموضوعات التي يفضلون قراءتها في الصحافة الإككترونية الموضوعات الاجتماعية وظهر ذلك بنسبة 62.3\% يلي ذلك الموضوعات الثقافية بنسبة 58.8\% ثم العلمية بنسبة 57\%، والدينية بنسبة 54.4 والسياسة بنسبة 45.6\% والاقتصادية\%29.8\% .أما الرياضية بنسبة 21.9 ويرجع ضعف نسبة متابعة الرياضة عبر الانترنت لأنهم يفضلون منابعة المباريات الرياضية عبر الفضائيات لأن النقل سيكون مباشر للمباريات.

جدول رقم (8)

يبين أهمية الموضوعات بالنسبة للمبحوثين

\begin{tabular}{|c|c|c|}
\hline النسبة المئوية & التكرار & الفئة \\
\hline 42.9 & 49 & مهمة جدا \\
\hline 50.9 & 58 & مهمة إلى حد ما \\
\hline 4.4 & 5 & لا ادري \\
\hline 1.8 & 2 & غير مهمة \\
\hline 100 & 114 & المجموع \\
\hline
\end{tabular}

يبين الجدول رقم (8) بأن الموضوعات التي يتابعها المبحوثين بالنسبة لهم مهمة لأن من ذكروا أنها مهمة إلى حد ما بلغت نسبتهم 50.9\% بينما من يرون أنها 


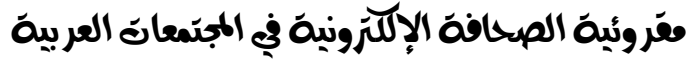

مهمة جداً بلغت نسبتهم 42.9\%. أما الذين لا يدرون نسبتهم 4.4\% أما من برون أنها غير مهمة 1.8\%.

\section{جدول رقم (9)}

يوضح مدى تفاعل المبحوثين مع المواد المنشورة

\begin{tabular}{|c|c|c|}
\hline النسبة المئوية & التكرار & الفئة \\
\hline 23.6 & 27 & دائهما \\
\hline 63.2 & 72 & أحيانا \\
\hline 13.2 & 15 & لا أتفاعل مطلقا \\
\hline 100 & 114 & المجموع \\
\hline
\end{tabular}

يوضح الجدول رقم (9) بأن أفراد العينة يتفاعلون مع المواد المنشورة في الصحف الإلكترونية أحياناً وظهر ذلك بنسبة 63.2\% بينما الذين بتفاعلون بصفة دائمة 23.6\% \%أما الذين لا يتفاعلون مطلقاً بلغت نسبتهم 13.2\% معنى ذلك أن \% 86.8 يتفاعلون مع الموضوعات المنشورة في الصحافة الإكترونية.

$$
\text { جدول رقم (10) - (10) }
$$

يبين الصعوية التي يجدها المبحوثين في فهم الموضوعات

\begin{tabular}{|c|c|c|}
\hline النسبة المئوية & التكرار & الفئة \\
\hline .9 & 1 & كثيراً \\
\hline 35.9 & 41 & إلى حدما \\
\hline 61.4 & 70 & لا أواجه صعوبة \\
\hline 1.8 & 2 & كثيراً جداً \\
\hline 100 & 114 & المجموع \\
\hline
\end{tabular}

الجدول رقم (10) يبين بأن 61.4\% من المبحوثثن لا يجدون صعوبة في فهر الموضوعات المنشورة في الصحافة الإلكترونية بينما 35.9\% يجدون صعوبة إلى حداً ما. بنما الذين يجدون صعوبة بلغت نسبتهم 2.7\%. أذن معظم المبحثين لا يجدون صعوبة في الإطلاع على الموضوعات المنشورة في الصحافة الإككترنية لأنها عادة تكون بأكثر من لغة، كما توجد خدمة الترجمة عبر Google . 
د. عغاف عبد الكر إسماعبله

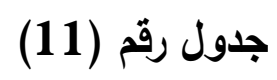

يبين العوامل التي تؤثر سلباً في مقروئية المبحوثين للصحافة الإكترونية

\begin{tabular}{|c|c|c|c|c|c|c|c|c|c|c|c|c|c|c|c|c|}
\hline \multicolumn{2}{|c|}{ عدمعلامات التريي } & \multicolumn{2}{|c|}{ ضغف اللةك } & \multicolumn{2}{|c|}{ استخدام أسايبي مقددة } & \multicolumn{2}{|c|}{ كثرة|الاخطاء } & \multicolumn{2}{|c|}{ 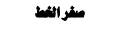 } & \multicolumn{2}{|c|}{ موقيع الموضيع } & \multicolumn{2}{|c|}{ تداخز التكابة } & \multicolumn{2}{|c|}{ انعدام وسائل الابراز } & \multirow{2}{*}{ الثمالم } \\
\hline$\%$ & التكراد & $\%$ & التكراد ل ال & $\%$ & 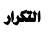 & $\%$ & 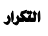 & $\%$ & التكرار ل إ & $\%$ & التكرا & $\%$ & 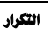 & $\%$ & التكراد & \\
\hline 22.8 & 26 & 51.7 & 59 & 35.9 & 41 & 45.6 & 52 & 29 & 33 & 35.9 & 41 & 53.5 & 61 & 47.4 & 54 & \\
\hline 39.5 & 45 & 28 & 32 & 50 & 58 & 38.6 & 44 & 49.1 & 56 & 46.5 & 53 & 32.4 & 37 & 39.5 & 45 & 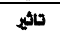 \\
\hline 6.1 & 7 & 5.3 & 6 & 1.8 & 1 & 4.4 & 5 & 4.4 & 5 & 5.3 & 6 & 5.3 & 6 & 3.5 & 4 & كائي \\
\hline 31.6 & 36 & 15 & 17 & 12.3 & 14 & 11.4 & 13 & 17.5 & 20 & 12.3 & 14 & 8.8 & 10 & 9.6 & 11 & إتاثير \\
\hline 100 & 114 & 100 & 114 & 100 & 114 & 100 & 114 & & 114 & 100 & 114 & 10 & 114 & 100 & 114 & جوب \\
\hline
\end{tabular}

يبين الجدول (11) بأن هنالك عوامل أثرت سلباً في مقروئية المبحوثين للصحافة الإلكترونية أكد 53.5\% تداخل الكتابة كان تأثنيرها قوي، 51.7\% ضعف اللغة،47.4\%انعدام وسائل الإبراز،45.6\% كثرة الأخطاء، و 35.9\% يرون أن السبب موقع الموضوع واستخدام أساليب معقدة، 29\% حجم الخط المستخدم في الكتابة،22.8\% لعدم وجود علامات ترقيم.

جدول رقم (12) - (12)

يوضح مقترحات المبحوثين لتحافظ الصحافة الإلكترونية على مكاتتها

\begin{tabular}{|c|c|c|c|c|c|c|c|c|c|c|c|c|c|c|}
\hline \multicolumn{2}{|c|}{ التاكل من المصادر } & \multicolumn{2}{|c|}{ إتاحة حرية التعبير } & \multicolumn{2}{|c|}{ تفعيل القوانيخ } & \multicolumn{2}{|c|}{ تشين تموضوعات } & \multicolumn{2}{|c|}{ زيادة التفاعلية } & \multicolumn{2}{|c|}{ الاهتام بالمشسون } & \multicolumn{2}{|c|}{ الاهتعامباتشكل } & \multirow{2}{*}{ 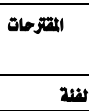 } \\
\hline$\%$ & التكرار & $\%$ & التكرار & $\%$ & التكرار & $\%$ & التكرار & $\%$ & التكرار & $\%$ & التكرار & $\%$ & التكرار & \\
\hline 20.2 & 23 & 14.9 & 17 & 13.2 & 15 & 8.8 & 10 & 9.6 & 11 & 15.8 & 18 & 9.6 & 11 & اوالقَبشدة \\
\hline 73.7 & 84 & 60.5 & 69 & 64 & 73 & 57 & 65 & 70.2 & 80 & 72.8 & 83 & 65.8 & 75 & اواقة \\
\hline 6.1 & 7 & 22.8 & 26 & 19.3 & 22 & 28 & 32 & 18.4 & 21 & 11.4 & 13 & 18.5 & 21 & أواقة إلى حدا \\
\hline 0 & 0 & 1.8 & 2 & 2.6 & 3 & 4.4 & 5 & .9 & 1 & 0 & 0 & 3.5 & 4 & لاواوق لاوق \\
\hline 0 & 0 & 0 & 0 & .9 & 1 & 1.8 & 2 & .9 & 1 & 0 & 0 & 2.6 & 3 & لاواوافق بشدة \\
\hline 100 & 114 & 100 & 114 & 100 & 114 & 100 & 114 & 100 & 114 & 100 & 114 & 100 & 114 & 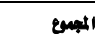 \\
\hline
\end{tabular}

تقدم أفراد عينة الدراسة بمقترحات بينها الجدول رقم ( 12) حيث يرى 73.7 ضرورة التأكد من المصادر، و 73\% يقترحون تفعيل قوانين الجرائم الإكترونية ، 72.8\% برون الاهتمام بالمضمون يجعل الصحافة الإلكترونية تحافظ على مكانتها، و 70.2\% ينادون بزيادة الفاعلية وطرح مزيد من طرق التواصل،60.5\% يقترحون زيادة المساحة المتاحة للحرية تشجع القراء على الإدلاء بآرائهم دون 


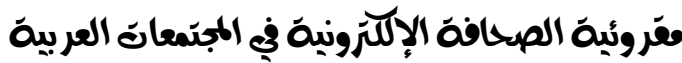

خوف •وثم ذكر المبحوثين من المقترحات أيضاً الاهتمام بالثكل وتضمين مواد تفسيرية.

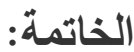

أولاً: النتائج

1. 62.2\% من أفراد العينة بقضون ما بين 2 إلى 4 ساعات في تصفح

الصحف الإكترونية بينما 30.8\% يقضون مابين 4 إلى 6 ساعات أما

$$
\text { الذين يمضون أكثر من } 6 \text { ساعات بلغت نسبتهم } 3.5 .
$$

2. أكثز مواقع التواصل الاجتماعي التي يستخدمه المبحوثين دائماً وأحياناً

الواتساب وظهر ذلك بنسبة 96.5\% ،ثم اليوتيوب بنسبة 92\% ، ثم

الفيسبوك بنسبة 83.3\% ، ثم الانستغرام بنسبة 74.6\% ، تويتز 64\%،

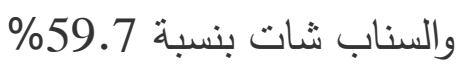

3. بينت الدراسة أن الذين يقرؤون الصحف الإكثرونية بأثكالها المختلفة

بنسبة \%87.6\%، 81.5\% المواقع الإخبارية 170.1\% المجلات

الإكترونية 51.7\% والمنتديات بنسبة 61.4\% والمدونات 58.7\%

4. وأوضح أفراد العينة بأنهم يقراعون صحفهم الإلكترونية المفضلة لتوفر

وسائل التفاعل مع الموضوعات والأسلوب المستخدم في الكتابة وظهر

$$
\text { ذلك بنسبة 49.1\%. }
$$

5. أن المبحوثين بأن أكثر الموضوعات التي يفضلون قراءتها في الصحافة

الإلكترونية الموضوعات الاجتماعية وظهر ذلك بنسبة 62.3\% .

6. 86.2\% من أفراد العينة يتفاعلون مع المواد المنشورة في الصحف

$$
\text { الإلكترونية. }
$$

7. أن 61.4\% من المبحوثين لا يجدون صعوبة في فهم الموضوعات

المنشورة في الصحافة الإككترونية. 
8. أكثر العوامل التي أثرت سلباً في مقروئية الصحافة الإكترونية كانت 53.5 تداخل الكنابة كان 51.7\% بسبب ضعف اللغة

ثانياً: التوصيات

1. ضرورة التأكد من صحة المعلومات التي تؤخذ من المصادر حتى لا تكون الصحف الإكترونية مصدراً للثائعات.

2. تفعيل قوانين الجرائم الإلكترونية، وتطبيق عقوبات رادعة لكل من يقوم بعمل ويصنف بأنه يتعارض مع القانون.

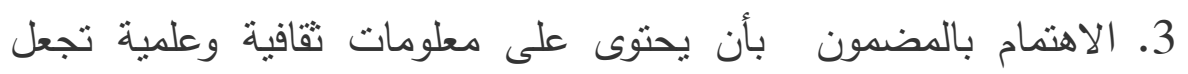
الصحافة الإكترونية تحافظ على مكانتها.

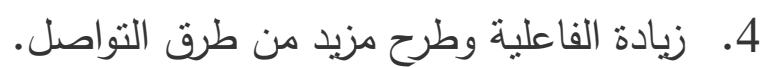

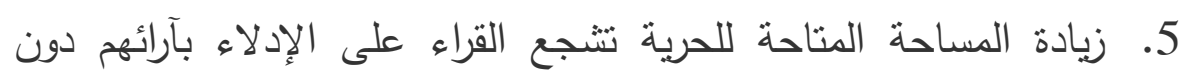
خوف . (- مان 6. الاهتمام بالثكل وتضمين مواد تفسيرية. 7. أن تهنم الصحف الإكترونية بأن يكون المسئولين عن إصدارها فئنسين فيبن في مجال تصميم المواقع بجانب مختصين في مجال التحرير •

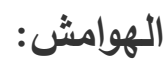

1عبدالعزيز بن ضيف الله الكناني الزهراني، مقروئية النصوص الإعلامية الإلكترونية، ،بحث

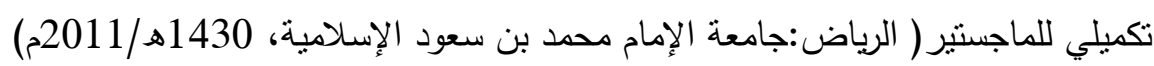
2درويش اللبان، الصحافة الإككرونية دراسات تفاعلية وتصميم المواقع، ط1 الدار المصرية

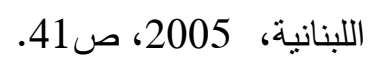

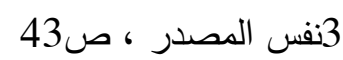

4مي العبد الله سنو، الاتصال في عصر العولمة، الدور والتحديات الجديدة ،الدار الجامعية

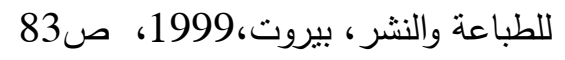




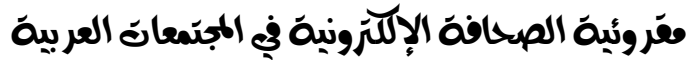

5حسين شفيق، الوسائط المتعددة وتطبيقاتها في الإعلام، ط2، رحمة برس للطباعة والنشر، 2006، ص ص 206 - 206

6مال بوعجيمي، بلقا سم بروان، الصحافة الإكترونية في الجزائر واقع و آفاق، جامعة الجزائر ، كلية العلوم السياسية و الإعلام، قسم علوم الإعلام والاتصال، 2005 ، ص07. 7درويش اللبان، مرجع سابق، ص26 8حسين شفيق، مرجع سابق، ص 47

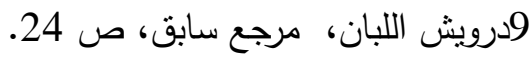

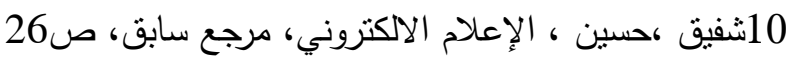

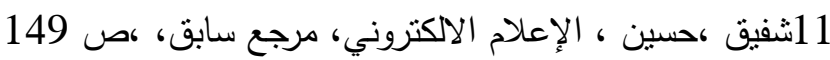

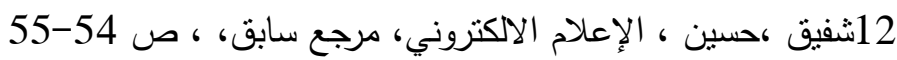

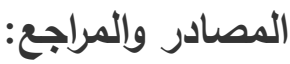

1. مي العبد الله سنو، الاتصال في عصر العولمة، الدور والتحديات الجديدة ،الدار الجامعية للطباعة والنشر ، بيروت، 1999. 2. محمود علم الدين، تكنولوجيا المعلومات و الاتصال ومستقبل صناعة الصحافة، السحاب للنشر والتوزيع، 2005. 3. حسين شفيق، الإعلام الالكتروني، دار الكتب العلمية للنشر و التوزبع،

$$
50 \text { شارع الثيخ ريحان، عابدين القاهرة، } 2005 .
$$

4. حسين شفيق، الوسائط المتعددة وتطبيقاتها في الإعلام، ط2، رحمة برس

$$
\text { للطباعة والنشر ، } 2006 .
$$

5. درويش اللبان، الصحافة الإلكترونية دراسات تفاعلية وتصميم المواقع، ط1 الدار المصرية اللبنانية، 2005 6. جمال بوعجيمي، بلقا سم بروان، الصحافة الإلكترونية في الجزائر واقع وآفاق، جامعة الجزائر، كلية العلوم السياسية والإعلام، قسم علوم الإعلام

$$
\text { والاتصال، } 2005 \text { ، ص07.07. }
$$




\section{د. عفاف عبد اللر إسماعيله}

7 ـ . عبدالعزيز بن ضيف الله الكناني الزهراني عبدالعزيز بن ضيف الهه الكناني الزهراني، مقروئية النصوص الإعلامية الإلكترونية ،بحث تكميلي للماجستير( الرياض:جامعة الإمام محمد بن سعود الإسلامية، 1430 هـ/ 2011

8. آمنه نبيح، ماهية الصحافة الإكترونية وعوامل تطورها، http://diae.net/6790\#content2017 